\title{
A Academia Brasileira de Letras e a institucionalização do academicismo no Brasil do final do século XIX
}

Maurício Silva I UNINOVE

Resumo: O presente artigo analisa as relaçōes dos autores brasileiros com a Academia Brasileira de Letras, destacando os processos de institucionalização do academicismo no Brasil do final do século XIX. Palavras-chave: literatura brasileira, Academia Brasileira de Letras, academicismo.

A questão da institucionalização da literatura no Brasil - e, especificamente, da literatura academicista - é um dos mais interessantes - embora menos estudados - temas relacionados à constituição do campo literário no Brasil do século XIX.

Em seu sucinto, mas denso artigo sobre o assunto, Jacques Dubois afirma que a institucionalização literária pressupõe pelo menos dois fenômenos indispensáveis: a) a existência de "instances de légitimation" da literatura; e b) a "articulation du système littéraire dans le système social". ${ }^{2}$ Com efeito, pode-se

1. Em português: "instâncias de legitimação". (Tradução do autor).

2. DUBOIS. In: DUCHET, 1979, p. 159. Em português: "articulação do sistema literário com o sistema social". (Tradução do autor). 
verificar a ocorrência de ambos os fenômenos no caso da literatura produzida no Brasil no final do século XIX e durante sua passagem para o século XX, num imbricamento quase indistinto entre eles. Começando com o segundo - a articulação entre os sistemas literário e social -, não é difícil perceber, nesse período, como essa articulação adquire concretude exatamente a partir do processo de institucionalização da Academia Brasileira de Letras e de uma literatura representativa de seu ideário estético. Sobre o primeiro - a existência de instâncias de legitimação literária -, pode-se afirmar que a própria Academia Brasileira de Letras, ao lado de outras instuições, como a imprensa, as livrarias, os centros acadêmicos e entidades culturais diversas, desempenhava esse papel, contribuindo decisivamente para a consolidação do cenário literário finissecular no Brasil.

\section{Academia e academicismo}

Desde pelo menos o século XVII, o Brasil conheceu um pródigo movimento academicista, que congregava diversos letrados. Tais movimentos propagaram-se por várias regiões e, em momentos diferentes, ditaram regras e/ou seguiram de perto cânones artísticos. No século XIX, agremiações semelhantes, mas com propósitos diversos, passaram a ser confundidas com certa oficialidade intelectual, e nesse sentido a Academia Imperial de Belas Artes (1816) pode ser tomada como uma precursora. Já no final desse mesmo século, com a criação da Academia Brasileira de Letras em 1896, pode-se dizer que começa a vigorar uma autêntica expressão literária academicista, que ganha também aura de estética oficial e compete, em condições desiguais, com tendências artísticas relativamente marginalizadas. Assim, se do ponto de vista estritamente institucional a Academia Brasileira de Letras apresenta pontos em comum com as academias do século XVIII, do ponto de vista histórico ela se inscreve no panorama da criação das grandes academias e institutos criados no Brasil a partir do século XIX, com o propósito declarado - mas nem sempre realizado de fato - de dar ao Brasil um sentido fundador, seja no campo das artes plásticas - com a criação da já citada Academia Imperial de Belas Artes -, seja no campo histórico e político - com a criação do Instituto Histórico e Geográfico Brasileiro em 1838 -, seja finalmente no âmbito da expressão literária - com a criação da própria Academia Brasileira de Letras.

Desse modo, a fundação da Academia Brasileira de Letras serviu como uma espécie de divisor de águas no âmbito da estética literária brasileira: de 
um lado, situavam-se os acadêmicos, cuja condição especial concedia-lhes um prestígio almejado por muitos autores e contribuía para a manutenção de um status quo; de outro lado, encontravam-se os não-acadêmicos, que além de precisarem angariar a atenção do público por méritos muito próprios, não possuíam as benesses e o reconhecimento da oficialidade artística e da sociedade em geral. É preciso lembrar, ainda, que um dos mais importantes movimentos acadêmicos surgidos no país - exatamente o que se deu em torno da Academia Brasileira de Letras - desponta numa época singular de indecisões estéticas ou, no mínimo, de ecletismo literário: ao mesmo tempo em que havia os estertores da estética realistanaturalista competindo com as inovações do movimento simbolista raramente reconhecido pela crítica e pouco permeável aos desejos do público, assistia-se à ascensão periférica de obras e autores que propunham uma renovação de fundo da literatura nacional, a que circunstancialmente deu-se o nome de pré-modernistas, já no início do século XX.

Nesse contexto, a Academia tornou-se, na época de sua fundação, uma referência artística incontestável. Foi objeto de desejo, ainda que não declarado, da maior parte de nossos escritores, mesmo daqueles cuja obra estava, reconhecidamente, distante dos cânones acadêmicos; deu prestígio aos eleitos e causou despeito em muito autor cujos méritos iam além do reconhecimento oficial. Do ponto de vista da expressão artística, mais do que de uma perspectiva social, o movimento academicista foi segregacionista: cooptou exclusivamente os autores que, de certo modo, enquadravam-se em seus padrões de fruição estética, alijando de suas lides os demais. Isso permite visualizar a Academia Brasileira de Letras, pelo menos durante o que se pode considerar o período áureo - suas primeiras duas décadas -, como uma agremiação esteticamente homogênea.

Embora a historiografia literária brasileira pareça ter rejeitado esse fato, o movimento academicista a que nos referimos foi também o responsável pela consolidação de uma práxis literária singular: ajudou a fortalecer determinadas tendências artísticas que, a certa altura, tornaram-se vigentes no cenário nacional. Determinadas atitudes estéticas passaram a ser compulsoriamente rejeitadas, enquanto outras eram acatadas pela oficialidade literária sem reservas; autores eram proscritos do rol dos eleitos, na medida em que outros eram agregados mesmo com uma visível deficiência criativa; os livros dos participantes da agremiação eram aceitos e divulgados como verdadeiras obras-primas, enquanto a produção artística daqueles que não faziam parte do círculo acadêmico acabavam dependendo, muitas vezes, da complacência dos editores e do público leitor. 
Inaugurou-se uma nova tendência literária a partir de um agrupamento menos aleatório do que a historiografia pôde sugerir: reunidos sob aspirações estéticas comuns, os acadêmicos puderam fazer valer, de forma incontestável, os ideais da literatura como sorriso da sociedade, cujos princípios podem ser resumidos nos seguintes conceitos: expressão mundana e diletante, fenômeno artístico visceralmente ligado a uma determinada oficialidade cultural e política, culto da forma em detrimento do conteúdo.

É no contexto histórico da Primeira República, com todas as contradições sociais e políticas que ele pressupõe, que a Academia Brasileira de Letras erigia-se como um ponto de referência necessário à vida cultural, conhecendo, nas primeiras décadas, sua época de maior prestígio e influência. ${ }^{3}$ A ela ligava-se também boa parte do poder constituído, o que lhe concedia o status de representante oficial da literatura brasileira: os autores que a ela se vinculavam estabeleciam, por extensão, um vínculo com o establishment político-administrativo da República, podendo inclusive - como aconteceu em muitos casos - desempenhar papéis burocráticos ligados à máquina do poder republicano. ${ }^{4}$ Logicamente, semelhante relação pressupunha uma reciprocidade: ao mesmo tempo em que os acadêmicos desempenhavam - tácita ou manifestamente - o papel de defensores do poder político vigente, disseminava-se a ideologia da autopreservação por meio da diferenciação/hierarquização das atividades literárias. Assim, de um ponto de vista pragmático, o autor acadêmico era considerado um elemento indispensável ao regime político e ao governo estabelecido, em oposição aos outros atores do cenário artístico sem expressão reconhecida; de um ponto de vista estético, defendiam-se, em quase todas as instâncias da vida cultural do país, os recursos literários empregados pelos acadêmicos: em geral, uma escrita empolada, de natureza classicizante, via de regra encomiástica e/ou edificante, quase sempre parnasiana; de um ponto de vista da construção literária e de sua recepção, privilegiava-se a literatura burguesa e elitista, em franca oposição a uma vertente popular, massificada, da expressão artística.

3. NEVES, 1940; LIMA, 1942; GALVÃO, 1937; LIMA NETO, 1942; PEIXOTO, 1923

4. MACHADO NETO, 1973; MICELI, 1977.

5. GOULEMOT; OSTER, 1992; VIALA, 1985; SÜSSEKIND, 1987; THIESSE, 1985 . 
Assim, como entidade reconhecida oficialmente, a Academia Brasileira de Letras agrupava em seu meio nomes ligados não apenas à oficialidade literária, mas sobretudo à oficialidade burocrática nacional e à sociabilidade burguesa. Pelo menos dois índices socioliterários podem comprovar semelhante assertiva: a rejeição de alguns boêmios assumidos entre os pares acadêmicos (como o demonstram os casos de Emílio de Meneses ou Lima Barreto) e a inclusão, entre os membros da Academia, de personalidades pelo controvertido critério dos expoentes (como revelam os casos de Lauro Müller ou Osvaldo Cruz). ${ }^{6}$ Indubitavelmente, estar de alguma forma ligado à Academia representava um considerável impulso no árduo caminho da fama e do reconhecimento literários, embora nem sempre isso tenha significado a permanência do acadêmico nos anais da literatura nacional mais consagrada. De qualquer maneira, para a época, importava bastante ter o nome associado à principal entidade cultural do país, oficializada sob o beneplácito do poder constituído, já que a não-inserção do literato entre os acadêmicos podia redundar - como, em muitos casos, aconteceu de fato - num indesejável ostracismo artístico pela via da marginalização. Isso fazia parte, sem dúvida, de uma estratégia de atuação literária que visava à diferenciação estética por meio de índices nãoartísticos na sua constituição, como a ocupação de cargos públicos, a participação de atividades literárias mundanas (conferências, saraus, jantares, salões mundanos), a colaboração freqüente na imprensa etc.

É certo que, após a segunda década do século XX, o academicismo e sua contrapartida institucional, a Academia Brasileira de Letras - entrou em franco declínio, causando mal-estar entre os autores empenhados em criar uma literatura de destaque na cultura brasileira; ainda em 1917, por exemplo, aqueles que, anos mais tarde, se agrupariam em torno de um ideário iconoclastamente modernista já tinham despertado para o interesse de se forjar uma consciência rigidamente antiacadêmica. Já nos primeiros anos da década de 1920, Amadeu Amaral apontava

6. EL FAR, 1997. A teoria dos expoentes - pela qual a Academia se comprometia a aceitar entre seus pares nomes que, embora não fossem direta e evidentemente ligados às letras, eram representativos da intelectualidade brasileira, isto é, eram expoentes da cultura nacional foi amplamente discutida pela maior parte dos intelectuais do período, acadêmicos ou não. Para um posicionamento favorável a essa teoria, ver PEIXOTO, 1947. Para um posicionamento contrário, ver AMADO, 1922.

7. BRITO, 1974.

8. AMARAL, 1976. 
para este declínio e, em 1918, Humberto de Campos $^{9}$ já sentia, entre a geração academicista (da qual ele mesmo participou intensamente) e a modernista, diferenças substanciais. Ao mesmo tempo, Afrânio Peixoto ${ }^{10}$ - um acadêmico modelar - confessava já não se sentir à vontade no ambiente acadêmico, excessivamente modificado pela nova realidade social e cultural por que passava o país. Não podemos esquecer, finalmente, o golpe de misericórdia dado num academicismo já em ruínas por um de seus mais eminentes representantes, Graça Aranha, que em retumbante discurso proferido em 1924 proclamava peremptoriamente, assinalando sua definitiva derrocada:

a fundação da Academia foi um equívoco e foi um erro [...] a Academia está no vácuo. Não tem função possível a exercer [...] se a Academia não se renova, morra a Academia. ${ }^{11}$

Eram os epígonos da Academia Brasileira de Letras evidenciando os seus estertores e assinalando os primeiros sinais de esgotamento da estética que vigorara incontestavelmente durante duas décadas na cultura brasileira.

\section{Academia: condições de institucionalização}

Antes, porém, desses primeiros sinais de decadência, a Academia viveu - como acabamos de sugerir - dias de glória ímpar, a ponto de, durante duas décadas, "regular" esteticamente a literatura nacional, impondo preceitos estéticos, mas também normas de comportamento que orientavam os artistas, bem como padrões de sociabilidade e princípios profissionais que acabavam por definir a importância e o status do escritor da época.

A Academia funcionava, nesse sentido, como uma entidade rigorosamente seletiva, espécie de órgão controlador de uma suposta qualidade estética a ser preservada como índice da intelectualidade brasileira e da condição

9. CAMPOS, 1935.

10. FILHO, 1972.

11. ARANHA, 1924, p. 230. Para a conturbada relação de Graça Aranha com a Academia, consultar SERRA, 2001. Cumpre assinalar que, por motivos diferentes do de Graça Aranha, João Ribeiro já tinha decretado, desde 1915, a sentença de morte da Academia (LEÃO, 1962). 
do país como nação civilizada. Assim, a principal preocupação dos acadêmicos voltava-se - ainda que não como uma ação programática ou, ao menos, conscientemente programática - para a institucionalização da Academia e, por extensão, de seus membros e dos ideais estéticos que professavam.

Para a Sociologia, a institucionalização deve ser vista sobretudo como um particular "proceso de cristalización continua de variados tipos de normas, de organizaciones y de esquemas reguladores de los procedimientos de intercambio de los diversos bienes". ${ }^{12}$ Mas, pode-se completar, uma instituição é algo muito mais complexo do que semelhante exposição sugere: pressupõe, além de um conjunto de normas e regulamentos, a existência de um corpo social definido e de desdobramentos institucionais, que são suas diversas esferas (política, econômica, religiosa, cultural etc). Finalmente, pode-se ainda apontar duas características próprias do processo de institucionalização e que nos interessam em particular: o fato de uma instituição, em geral, surgir do "impact of novel circunstances upon ancient custom" e a constatação de que "in its ideal likeness an institution usually creates its apology".

É possível fazer uma singular aproximação entre a definição sociológica da instituição e nossa percepção do processo de constituição da estética academicista. Feitas as devidas adaptações e salvaguardadas as necessárias especificidades de cada caso, tínhamos no último quartel do século XIX todas as condições para que a Academia Brasileira de Letras emergisse como a principal instituição cultural do período: um conjunto de normas e regulamentos (preceitos éticos e estéticos, prescritos em seus estatutos e regimentos ou simplesmente subentendidos em condutas e sanções diversas), um corpo social definido (seus membros e sua sede física) e, finalmente, sua inclusão numa ampla esfera cultural que pode ser representada pela literatura brasileira.

Além disso, ela surge do impacto de novas condições de criação e divulgação literárias, sustentando todo um ideário encomiástico voltado para a

12. EISENSTADT, 1975, p. 95. Em português: "processo de cristalização contínua de vários tipos de normas, de organizações e de esquemas reguladores dos procedimentos de intercâmbio dos diversos bens". (Tradução do autor).

13. HAMILTON. In: SELIGMAN; JOHNSON, 1935, p. 86. Em português: "impacto de circunstâncias originais sobre um costume antigo" e "em sua forma ideal uma instituição cria comumente sua apologia”. (Tradução do autor). 
opologia sua e de seus pares. Com efeito, parece-nos um truísmo destacar semelhante evidência, já que se trata de um consenso regido pelas próprias marcas de sua gênese: sua criação por literatos relevantes da época, a denominação explícita que recebeu, indicando seu vínculo indelével com a sociedade letrada, o papel que desempenhou no cenário literário nacional (com concursos, edições, encargos oficiais etc). Particularmente, sobre a questão dos esquemas reguladores, cumpre lembrar que a Academia Brasileira de Letras foi, desde sua fundação, regida por regras formalmente estatuídas, quando então se definiu quais seriam as principais normas a serem obedecidas por seus membros, bem como se traçaram os principais objetivos da instituição, particularmente o incentivo e a preservação "da língua e da cultura nacional".

Resta-nos uma questão relevante: a de seu corpo social, que, ao lado do que aqui denominamos ideário encomiástico, é condição sine qua non para que se possa declarar legítima a existência de uma instituição. Como já referimos anteriormente, a Academia constituiu-se, a princípio, numa singular espécie de agremiação literária, com sede própria, embora instável em seus primeiros anos, e com um conjunto de quarenta membros rigorosamente selecionados, a exemplo do que ocorria na similar francesa, que tomara como modelo assumido. ${ }^{15}$ Mas suas particularidades, nesse aspecto, vão além desse fato prosaicamente formal: mais interessante do que isso é observar como a Academia buscou resolver, internamente, as contradições que perpassavam um corpo social muito mais amplo e complexo e no qual, em última instância, ela se assentava: a sociedade da República das Letras.

Com efeito, era caleidoscópico o contexto social no que concerne à atuação do escritor brasileiro: vivia-se numa época em que se misturavam, num mesmo cenário cultural, os guardiães de estéticas passadistas, escrevinhadores marginais, orgulhosos plumitivos, jovens literatos com propostas de renovação estética, boêmios idealistas, medalhões da literatura e escritores profissionais. Mas a nem todos estavam destinados os assentos consagradores da Academia, já que apenas alguns poucos - que, via de regra, compactuavam de um ideário estético semelhante - podiam desfrutar dos privilégios concedidos aos membros da corporação acadêmica. Os boêmios ou os humoristas declarados, os nefelibatas ou os independentes, por exemplo, eram compulsoriamente alijados das hostes

14. ACADEMIA BRASILEIRA DE LETRAS, 1917, p. 5.

15. SIGNER, 1988; TAVARES, 1979. 
acadêmicas, o que revela, como sugerimos, não apenas um empenho na preservação do corpo social instituído, mas uma cooptação rigorosamente seletiva. Foram, nesse sentido, muitos os recusados: do decadentista baudelairiano Fontoura Xavier ao independente marginalizado Lima Barreto, do temeroso satírico Bastos Tigre ao iconoclasta Antônio Torres, do simbolista dipsomaníaco B. Lopes ao poeta e cancionista popular Orestes Barbosa, todos aqueles que não compartilhavam dos mesmos ideais éticos e estéticos da Academia acabavam vetados pela proverbial sisudez acadêmica.

E tudo, é bom que se saliente, sob o beneplácito de seu presidente vitalício, Machado de Assis, que representava, nas palavras de Beatriz Jaguaribe, "O homem da polidez respeitável e da preservação institucional". ${ }^{16}$ O caso mais célebre talvez seja o de Emílio de Meneses: conhecido pela irreverência e sua vida assumidamente boêmia, teve sua candidatura vetada por Machado de Assis, que via nele o exemplar mais acabado da irresponsabilidade discordante do sério papel de representante das letras nacionais. De acordo com o testemunho de Rodrigo Octávio, que nos conta esse episódio, Machado de Assis entendia que "a Academia devia ser, também, uma casa de boa companhia; e o critério das boas maneiras, da absoluta respeitabilidade pessoal, não podia, para ele, ser abstraído dos requisitos essenciais para que ali se pudesse entrar". ${ }^{17}$

Mais do que as noções de polidez e de responsabilidade, reputação talvez seja a palavra-chave nesse contexto: o acadêmico deveria ser, sobretudo, homem de inabalável reputação literária e pessoal, a fim de que pudesse compartilhar das benesses oferecidas a seus pares pelo ambiente acadêmico. Para José Veríssimo, por exemplo, que participara ativamente da fundação da Academia e se destacava como um de seus membros mais atuantes, a instituição acadêmica surgia com o propósito de ser uma entidade destinada à "consagração das reputações literárias". 18

Evidentemente, tais reputações faziam-se num sintomático ambiente de mútua ajuda, revelando uma espécie de corporativismo própria de uma instituição seletiva e fechada, como era a Academia. Um agrupamento de literatos singular como esse não podia deixar de lado o tão afamado corporativismo, forjando

16. JAGUARIBE, 1998 , p. 37.

17. OCTÁVIO, 1979, p. 54; MENEZES, 1945.

18. VERÍSSIMO, 1897, p. 313. 
reputações por meio de favores, influências e proteções: quando secretário da Fazenda do Rio de Janeiro, Coelho Neto, por exemplo, não hesitou em angariar emprego para vários amigos, colocando-os no circuito das boas relações profissionais e políticas; Machado de Assis, igualmente, não medira esforços ao prestigiar a polêmica candidatura de Mário de Alencar para a Academia; o Barão do Rio Branco, por sua vez, agiria em favor de Euclides da Cunha na vaga para professor do Colégio D. Pedro II; Joaquim Nabuco, a exemplo de Machado, usaria sua influência para beneficiar a candidatura de Graça Aranha à Academia; Medeiros e Albuquerque nomearia Valentim Magalhães e José Veríssimo para cargos oficiais. ${ }^{19}$ Portanto, para a ética acadêmica, os limites entre uma reputação conquistada a duras penas e de modo independente e aquela que nascia de favorecimentos diversos era muito tênue, já que os meios justificavam os fins.

Assim era formado o corpo social de uma das mais prestigiadas instituições do período. Mas o fato é que o academicismo representava uma legitimação de sua personagem social, dando realce ao papel do escritor como regulador de uma estética e de uma norma lingüística, bem como de uma ética de conduta social, o que acabava permitindo que, indiretamente, além de legitimar, a Academia tutelasse parte da produção intelectual e literária do período.

A atividade de escritor, que, desde a Independência - quando uma atuação literária mais intensa se desenvolve no Brasil -, era marginalizada, pouco rentável e instável, começa a sofrer sensível alteração, sobretudo a partir da fundação da Academia Brasileira de Letras, quando se assiste a uma "organização durável e institucionalizada dos escritores consagrados". ${ }^{20}$ Nesse sentido, a entrada para a Academia representava prestígio e reconhecimento, transformando um escritor "marginal" em institucional e abrindo portas diversas para benefícios legais, como aliás já ressaltou Nicolau Sevcenko:

a Academia Brasileira, com o seu condão de consagrar os escritores, garantindo-lhes crédito total em qualquer casa editora do Rio, mas sobretudo colocando-os sob a tutela protetora do Estado, tornou-se um reduto de estabilidade no qual todos lutam para entrar. ${ }^{21}$

19. NEEDELL; MACHADO NETO, 1973; MICELI, 1977; SÜSSEKIND, 1987; BROCA, 1960.

20. MÉRIAN, 1988, p. 385.

21. SEVCENKO, 1989, p. 101 
De fato, a concorrência era árdua e demandava uma larga rede de relações sociais, mais do que literárias, como já se sugeriu uma vez: "o academismo sempre foi um fenômeno tanto (ou mais) social quanto cultural, mormente no caso da literatura". ${ }^{22}$, mais do que isso, a aceitação de um escritor pela Academia Brasileira de Letras podia inclusive corresponder, nas condições aqui esboçadas, a uma entrada para o cânone literário brasileiro, já que a canonização de um autor pela historiografia nacional depende, não poucas vezes, desse complexo processo institucional.

Um exemplo desse prestígio adquirido pelo acadêmico, das vantagens institucionais de que ele desfrutava e do benefício pessoal que a institucionalização the conferia era a possibilidade de se colocar, na folha de rosto dos livros publicados, logo abaixo do nome do autor, a sugestiva chancela "da Academia Brasileira de Letras", como que conferindo à obra ali apresentada um peso institucional e, conseqüentemente, um valor literário supostamente maior. A colocação nos livros da chancela acima referida, aliás, parece ter mais um efeito: instaura uma nova legibilidade, apontando ao leitor a clave pela qual se quer que o livro seja lido e recebido, pois, como afirma Roger Chartier, no rastro de Jauss, "uma nova legibilidade pressupõe um novo horizonte de recepção". ${ }^{23}$

Evidentemente, todos os fatores aqui arrolados, que, de certo modo, contam - no cômputo geral - a favor dos literatos acadêmicos, não impediam que, mesmo entre os mais preclaros representantes da Academia, se disseminasse uma visão contundentemente pessimista do quadro literário nacional, marcado, na opinião dos escritores da época, pelo mais constrangedor desinteresse por parte do público leitor; desinteresse, aliás, em grande medida, resultante dos altos índices de analfabetismo no Brasil que, entre os últimos anos do século XIX e primeiros do XX, ficaram entre setenta e oitenta por cento da população, o que resultaria, nas palavras de Antonio Candido, numa "literatura sem leitores".

José Veríssimo, por exemplo, afirmava, no alvorecer do novo século, ser a Literatura Brasileira uma "literatura de poucos, interessando a poucos", 25

22. CAVALIERI, 1990, p. 23.

23. CHARTIER, 1996, p. 81; JAUSS, 1994.

24. CÂNDIDO, 1985, p. 82; NAGLE, 1976; LAJOLO; ZILBERMAN, 1996; SEVCENKO, 1982.

25. VERÍSSIMO, citado por SEVCENKO, 1989, p. 88. 
enquanto que em 1892 Aluísio Azevedo traçava um diagnóstico igualmente desanimador da mesma literatura: "infelizmente a vida literária de hoje no Brasil é uma cousa tão hipotética como a vida elegante na costa d'África”. ${ }^{26}$ Até mesmo uma publicação como a célebre Revista Brazileira, na sua segunda fase, traçava um quadro não menos pessimista do que os anteriores, ao proferir o seguinte diagnóstico no editorial de seu primeiro número:

o povo brazileiro - não é sem magoa que o dizemos [...] não está ainda preparado para consumir o livro, substancial alimento das organizações virís e fortemente caracterisadas. Faltam-lhe as condições de gosto, instrucção, meios, saudavel direcção de espirito, sem as quaes não se pode cumprir a livre obrigação [...] de comprar, ler e entender verdades ou idéas colligidas em um volume, cuja leitura demanda largo folego e cujo estudo requer tempo de que o povo em geral não dispõe. ${ }^{27}$

Mas, mesmo num contexto tão desabonador para o escritor brasileiro, o papel da Academia Brasileira de Letras parece ter sido positivo, trazendo vantagens inauditas para o seu corpo social, um papel que ganha mais relevo ao levarmos em consideração uma série de acontecimentos socioculturais - além, evidentemente, do já citado analfabetismo - que, no conjunto, contribuíam para o agravamento da situação: a concorrência da produção literária nacional com os folhetins franceses e ingleses e com a literatura portuguesa, a proliferação das revistas ilustradas efêmeras, a falta de profissionalismo por parte de alguns escritores, excessivamente arraigados a algumas práticas boêmias, a escassez de editores e livrarias, a concentração das atividades culturais nos grandes centros urbanos. Tudo isso apontava, inegavelmente, para uma espécie de depauperação endêmica da literatura nacional, mas, em contrapartida, tornava mais relevante o aparecimento e a manutenção de uma entidade representativa da sociedade letrada como era, na época, a Academia Brasileira de Letras, a qual, a partir de então, será vista como uma tábua de salvação da literatura nacional, aumentando, de um lado, o prestígio do escritor nativo e conseguindo, de outro lado, impor uma cartilha ética e estética pela qual todos teriam de se orientar.

26. AZEVEDO, 1938, p. 60.

27. ANÔNIMO, 1879, p. 6. 


\section{Conclusão}

A Academia passa, assim, a ostentar uma importância que se vai perpetuar ao menos pelas duas décadas seguintes, transferindo aos literatos que abrigava todo o prestígio de uma entidade que, cada vez mais, se firmava como a principal instituição cultural do período, ainda que, de um ponto de vista sociológico e pragmático, a literatura fosse relegada a um segundo plano em relação à própria vida literária, como sugerem alguns estudiosos do período, como João Carlos Rodrigues, para quem "embora a existência ou não de uma literatura nacional ainda fosse motivo de discussão entre os críticos, os literatos, estes sim existiam, ninguém podia negar [...] Com a fundação da Academia Brasileira de Letras, eles passaram a adquirir importância”; ${ }^{28}$ ou Nelson Werneck Sodré, ao afirmar que

as camadas cultas, no fim do século XIX, permanecem ilhadas, impotentes os seus elementos para se realizarem como tais [...] Daí a preponderância da vida literária sobre a obra literária e o esforço de congregação que se resolve com a fundação da Academia Brasileira de Letras, em 1896, correspondendo, na sua tendência à seleção e ao brilho social, à tentativa de suprir aquilo que a ausência de público impedia que fosse proporcionado aos que se davam às letras [...] Mas a verdade é que, de certo modo, correspondia à tradição eminentemente literária de nossa cultura essa instituição que valorizava indivíduos e lhes conferia o brilho que suas obras não lhes podiam conferir. ${ }^{29}$

Enfim, as palavras com que Daniel Roche procura ilustrar a constituição das academias francesas do século XVIII, principalmente a Academia Francesa, modelo da brasileira, parecem servir literalmente à situação da Academia Brasileira de Letras, resumindo sua conformação:

trois éléments, qui vont dominer la vie académique du XVIII siècle, se mettent alors en place: un modèle statutaire qui définit le droit et révèle la mentalité du milieu académiste, un type de liaison continue avec le pouvoir [...], le contrôle des formes d'expression et la maittrise d'une

28. RODRIGUES, 1996, p. 53

29. SODRÉ, 1979 , p. 52. 
langue normalisée et unifiée qui fondamentalement distingue un type humain, moral et social, précise une éthique civique et culturelle à la fois. ${ }^{30}$

Embora a problemática academicista seja mais complexa do que esse pequeno entrecho sugere, ele parece resumir bem os principais conceitos que norteiam a constituição do academicismo de um modo geral e, coincidentemente, aquele que se forjou na passagem do século.

Abstract: The present article analyzes the relationship of the brazilian writers between the Brazilian Academy of Letters, detaching the institutionalizations issues on the nineteenth century in Brazil. Keywords: brazilian literature, Brazilian Academy of Letters, academicism.

\section{Referências Bibliográficas}

ACADEMIA BRASILEIRA DE LETRAS. Estatutos, regimento interno e regulamento dos concursos da Academia Brasileira de Letras. Rio de Janeiro: Jornal do Commercio, 1917.

AMADO, Gilberto. Apparencias e realidades. São Paulo: Monteiro Lobato \& C., 1922.

AMARAL, Amadeu. O elogio da mediocridade: estudos de notas e literatura. São Paulo: Hucitec, 1976.

ANÔNIMO. A Revista Brazileira. Revista Brazileira, Rio de Janeiro, Tomo I, n. 01, p. $05-07,1879$.

ARANHA, Graça. O Espírito Moderno. Revista da Academia Brasileira de Letras, Rio de Janeiro, Ano XV, n. 31, p. 225-241, jul. 1924.

AZEVEDO, Aluísio. O touro negro. Rio de Janeiro: Briguiet, 1938.

BRITO, Mário da Silva. História do Modernismo Brasileiro: antecedentes da Semana de Arte Moderna. Rio de Janeiro: Civilização Brasileira, 1974.

BROCA, Brito. A vida literária no Brasil: 1900. Rio de Janeiro: José Olympio, 1960.

30. ROCHE, 1988, p. 159. Em português: "três elementos, que vão dominar a vida acadêmica do século XVIII, são colocados então em questão: um modelo estatutário, que define o direito e revela a mentalidade do meio academicista, um tipo de elo contínuo com o poder [...] o controle das formas de expressão e o domínio de uma língua normatizada e unificada que, fundamentalmente, distingue um tipo humano, moral e social, ao mesmo tempo em que define uma ética cívica e cultural." (Tradução do autor). 
CAMPOS, Humberto de. Crítica: primeira série. Rio de Janeiro: José Olympio, 1935.

CANDIDO, Antonio. Literatura e sociedade: estudos sobre teoria e história literária. São Paulo: Nacional, 1985.

CAVALIERI, Ruth Villela. Academia de Letras: sobrevivência, ludismo e ritualização. 1990. 192f. Tese (Doutorado em Letras) - Pontifícia Universidade Católica, Rio de Janeiro, 1990.

CHARTIER, Roger (Org.). Práticas de leitura. São Paulo: Estação Liberdade, 1996.

DUBOIS, Jacques. Vers une théorie de l'institution. In: DUCHET, Claude et al. Sociocritique. Paris: Nathan, 1979.

EISENSTADT, Shmuel N. Instituciones Sociales. In: SILLS, David L. Enciclopedia Internacional de las Ciencias Sociales. Madrid: Aguilar, v. 6, 1975. p. 85-95

EL FAR, Alessandra. A encenação da imortalidade: uma análise da Academia Brasileira de Letras nos primeiros anos da República (1897-1924). 1997. 289f. Dissertação (Mestrado em Ciência Social) - Faculdade de Filosofia, Letras e Ciências Humanas, Universidade de São Paulo, São Paulo, 1997.

GALVÃO, Francisco. A Academia de Letras na intimidade. Rio de Janeiro: A Noite, 1937.

GOULEMOT, Jean M.; OSTER, Daniel. Gens de lettres, écrivains et bohèmes: l'imaginaire littéraire, 1630-1900. Paris: Minerve, 1992.

HAMILTON, Walton H. Institution. In: SELIGMAN, Edwin R. A.; JOHNSON, Alvin. Encyclopaedia of the Social Sciences. New York: Macmillan, 1935. v. 8, p. 84-89.

JAGUARIBE, Beatriz. Subjetividades Urbanas em Pompéia, Machado e Lima Barreto. In: ___ Fins de século: cidade e cultura no Rio de Janeiro. Rio de Janeiro: Rocco, 1998. p. 96-111.

JAUSS, Hans Robert. A bistória da literatura como provocação à Teoria Literária. São Paulo: Ática, 1994.

LAJOlO, Marisa; ZILBERMAN, Regina. A formação da leitura no Brasil. São Paulo: Ática, 1996.

LEÃO, Múcio. João Ribeiro. Rio de Janeiro: Livraria São José, 1962.

LIMA NETO, Joaquim Bento Alves de. Academia Brasileira de Letras. São Paulo: [s.n.], 1942 .

LIMA, Joaquim Bento Alves de. Academia Brasileira de Letras. São Paulo: Revista dos Tribunais: 1942.

MACHADO NETO, Antônio Luiz. Estrutura social da República das Letras: sociologia da vida intelectual brasileira, 1870-1930. São Paulo: Grijalbo; Edusp, 1973.

MENEZES, Raimundo de. Emílio de Meneses: o último boêmio. São Paulo: Martins, 1945.

MÉRIAN, Jean-Yves. Aluísio Azevedo: vida e obra (1857-1913). O Verdadeiro Brasil do Século XIX. Rio de Janeiro: INL, 1988.

MICELI, Sérgio. Poder, sexo e letras na República Velha: estudo clínico dos anatolianos. São Paulo: Perspectiva, 1977.

MOTTA FILHO, Cândido. Contagem regressiva: memórias. Rio de Janeiro: José Olympio, 1972. 
NAGLE, Jorge. Educação e sociedade na primeira República. São Paulo: EPU, 1976. NEEDELL, Jeffrey D. Belle Époque Tropical: sociedade e cultura de elite no Rio de Janeiro na virada do século. São Paulo: Companhia das Letras, 1993.

NEVES, Fernão. A Academia Brasileira de Letras: notas e documentos para a sua história (1896-1940). Rio de Janeiro: Publicações da Academia Brasileira, 1940.

OCTÁVIO, Rodrigo. Minhas memórias dos outros: nova série. Rio de Janeiro: Civilização Brasileira, 1979.

PEIXOTO, Afrânio. A Academia Brasileira. Revista da Academia Brasileira de Letras, Rio de Janeiro, Ano XIV, n. 25/26, p. 23-44, jan.-jun. 1923.

PEIXOTO, Afrânio. Poeira da estrada: ensaios de crítica e de história. Rio de Janeiro: W. M. Jackson, 1947.

ROCHE, Daniel. Les Républicains des Lettres: gens de culture et lumières au XVIII Siècle. Paris: Fayard, 1988.

RODRIGUES, João Carlos. João do Rio: uma biografia. Rio de Janeiro: Topbooks, 1996.

SERRA, Tânia. Graça Aranha e a Academia Brasileira de Letras. Projeto Memória de Leitura, Unicamp, Campinas, p. 01-09. Disponível em: <http://www.unicamp.br/ $\mathrm{iel} /$ histlist/tserra2.html>. Acesso em: 2001.

SEVCENKO, Nicolau. O fardo do homem culto: literatura e analfabetismo no prelúdio republicano. Almanaque: cadernos de literatura e ensaio, São Paulo, n. 14, p. 8083, 1982.

SEVCENKO, Nicolau. Literatura como missão: tensões sociais e criação cultural na primeira República. São Paulo: Brasiliense, 1989.

SIGNER, Rena. Academia Brasileira de Letras: nacionalismo à francesa. 1988. $174 \mathrm{f}$. Dissertação (Mestrado) - Faculdade de Filosofia, Letras e Ciências Humanas, Universidade de São Paulo, São Paulo, 1988.

SODRÉ, Nelson Werneck. Síntese de bistória da cultura brasileira. Rio de Janeiro: Civilização Brasileira, 1979.

SÜSSEKIND, Flora. Cinematógrafo de Letras: literatura, técnica e modernização no Brasil. São Paulo: Companhia das Letras, 1987.

TAVARES, Aurélio de Lyra. Brasil-França, ao longo de 5 Séculos. Rio de Janeiro: Biblioteca do Exército, 1979.

THIESSE, Anne-Marie. Les Infortunes Littéraires. Carrières des Romanciers Populaires à la Belle Époque. Actes de la Recherche en Sciences Sociales, n. 60, p. 31-46, Nov. 1985.

VERÍSSIMO, José. Noticias de Sciencias, Letras e Artes. Revista Brazileira, Rio de Janeiro, Tomo Nono, p. 313, 1897.

VIALA, Alain. Naissance de l'Écrivain: sociologie de la Littérature à l'Âge Classique. Paris: Minuit, 1985. p. 311-313. 